\title{
EXCURSÃO À ARRÁBIDA
}

No domingo, 12 de Março, organizou-se uma excursão à Arrábida, pequena unidade natural perfeitamente individualizada, que suscita sempre curiosidade pelo vigor das formas, pela originalidade da vegetação, pela variedade da ocupação humana.

Como tantas vezes acontece, o geólogo ou o geógrafo são obrigados a criar um nome de conjunto, alargando o seu sentido inicial nem sempre preciso, como é o presente. A cordilheira, que se vê de todos os pontos altos cerrando o horizonte de Lisboa pelo sul, desde o morro de Palmela ao planalto do Espichel, nunca teve qualquer designação que a cobrisse toda. Arrábida é pròpriamente a mais maciça e mais elevada das colinas calcárias, que culmina no Formosinho a $501 \mathrm{~m}$. Foi Choffat quem estendeu o nome a toda a «cadeia» montanhosa, numa memória excelente de estratigrafia e tectónica, que constitui a base do estudo geomorfológico da pequena região (1908). Num «esboço geográfico» breve e antiquado utilizei a designação no mesmo sentido (1935). Recentemente, foi publicada a folha geológica de Setúbal, que abrange a Arrábida e os terrenos adjacentes, levantada em parte, coordenada e com notícia explicativa por G. ZBYszewski (1964). Como não mais deixei de interessar-me pelo meu primeiro terreno de estudo e como aí dirigi numerosas excursões, fui acumulando observações e interpretações, condensadas na presente notícia. 
EVOLUÇĀO GEOLÓGICA E MATERIAIS DO RELEVO

A Arrábida está limitada tanto pelas suas alterosas arribas como pelo contraste, muito vigoroso, entre o conjunto de materiais fortemente enrugados e a planura onde, de um modo geral, as camadas de areias com leitos ou lentilhas de seixos não foram sensivelmente deslocadas. Numa área de $35 \mathrm{~km}$ de comprimento por $6 \mathrm{~km}$ de largura média encontra-se um verdadeiro museu de formas estruturais, cuja chave é dada, em grande parte, pela evolução geológica e pela natureza dos materiais do relevo (fig. 1). As linhas essenciais podem esquematizar-se assim:

1) Presença de espessas camadas de margas cor de borra de vinho, gipsíferas, infraliásicas, que só surgem em condições excepcionais mas constituem o substrato plástico das carapaças calcárias e explicam o vigor de certos acidentes tectónicos. Esta formação depositou-se num litoral, ora invadido pelo mar ora formando lagunas sujeitas a evaporação intensa e sede de activa precipitação química.

2) Sucede-lhe um franco aprofundamento do mar, onde se sedimentam, durante o resto do Lias e todo o Dogger, camadas de calcários, dolomíticos e siliciosos na base, geralmente escuros, brancos e compactos na maior parte, às vezes mais ou menos margosos no topo. Pela grande espessura que alcançm (algumas centenas de metros), este conjunto forma a ossatura do relevo e constitui ora o material das arribas ora a parte principal dos montes mais alterosos. Os calcários brancos são excelente material de construção, explorados a leste e a oeste de Santana: os lugares de Pedreiras de Cima e de Baixo nasceram desta actividade. A fábrica de cimento do Outão, uma das mais importantes do país, emprega as camadas margosas do topo e os enormes buracos das suas pedreiras mordem cada vez mais fundo no flanco do relevo.

3) No Neojurássico começa o enrugamento da Arrábida e a emersão dos primeiros anticlinais: no sopé dos relevos assim formados depositam-se grandes taludes de escombreiras, enriquecidos com acarreios de blocos siliciosos, oriundos do maciço antigo, de que restam algumas «ilhas» afogadas na bacia terciária do Sado: os elementos mais próximos estarão debaixo de espessas camadas de sedimentos, constituindo o fundo da bacia. Os materiais do Neojurássico formam camadas alternantes de calcários, arenitos e brechas, assentes, em nítida discordância angular, sobre os calcários anteriores que lhes ministraram parte do material. A esta brecha, no geral bem consolidada, dá-se, na construção, o nome de «mármore da Arrábida»: de um belo efeito decorativo pela variedade de cores dos elementos e pelo tom róseo do cimento, foi largamente usada nos templos de Setúbal e de Lisboa e constitui o material do monumento mais importante daquela cidade: a igreja manuelina de Jesus.

Os primeiros movimentos afectaram apenas os dois terços orientais da cordilheira e não se fizeram sentir além de Sesimbra: a sedimentação do Neojurássico, na área do Cabo, é marinha e concordante com as camadas anteriores: apenas a cambiante margosa do calcário indicará mar menos profundo e acarreios detríticos continentais. A discordância angular observa-se entre o Neojurássico e o Cretácico (bem visível no entalhe da enseada de Lagosteiros), indicando movimentos mais tardios e a persistência do mar a ocidente.

4) $O$ regime de emersão deve ter continuado durante o Cretácico e o Paleogénico, com retornos episódicos de um mar pouco profundo e grandes acarreios de material silicioso proveniente do maciço antigo, no geral muito mais grosseiro e menos rolado quando se caminha para leste. Numa fácies predominantemente detrítica encontram-se bancadas ou lentilhas calcárias e margosas, alimentadas talvez pela rápida alteração das escombreiras provenientes do relevo, apenas conservadas no sopé, onde o Neojurássico está em contacto com a principal fonte dos seus conglomerados. Na área do Cabo, pelo contrário, o mar deve ter-se mantido durante o Cretácico, exclusivamente constituído por arenitos grosseiros. As lacunas e irregularidades da sedimentação indicam a instabilidade da área da Arrábida. As injecções de rochas básicas dos arredores de Sesimbra, provàvelmente contemporâneas do «maciço subvulcânico» de Sintra (MATos Alves) e das efusões subaéreas dos arredores de Lisboa, fazem ascender a este periodo a instabilidade diapírica que se prolongou, muito provàvelmente, até ao fim do Pliocénico. O conjunto de formações detríticas, do Neojurássico ao Paleogénico, envolve os maciços calcários e bifurca-se em torno do monte de São Luís. 

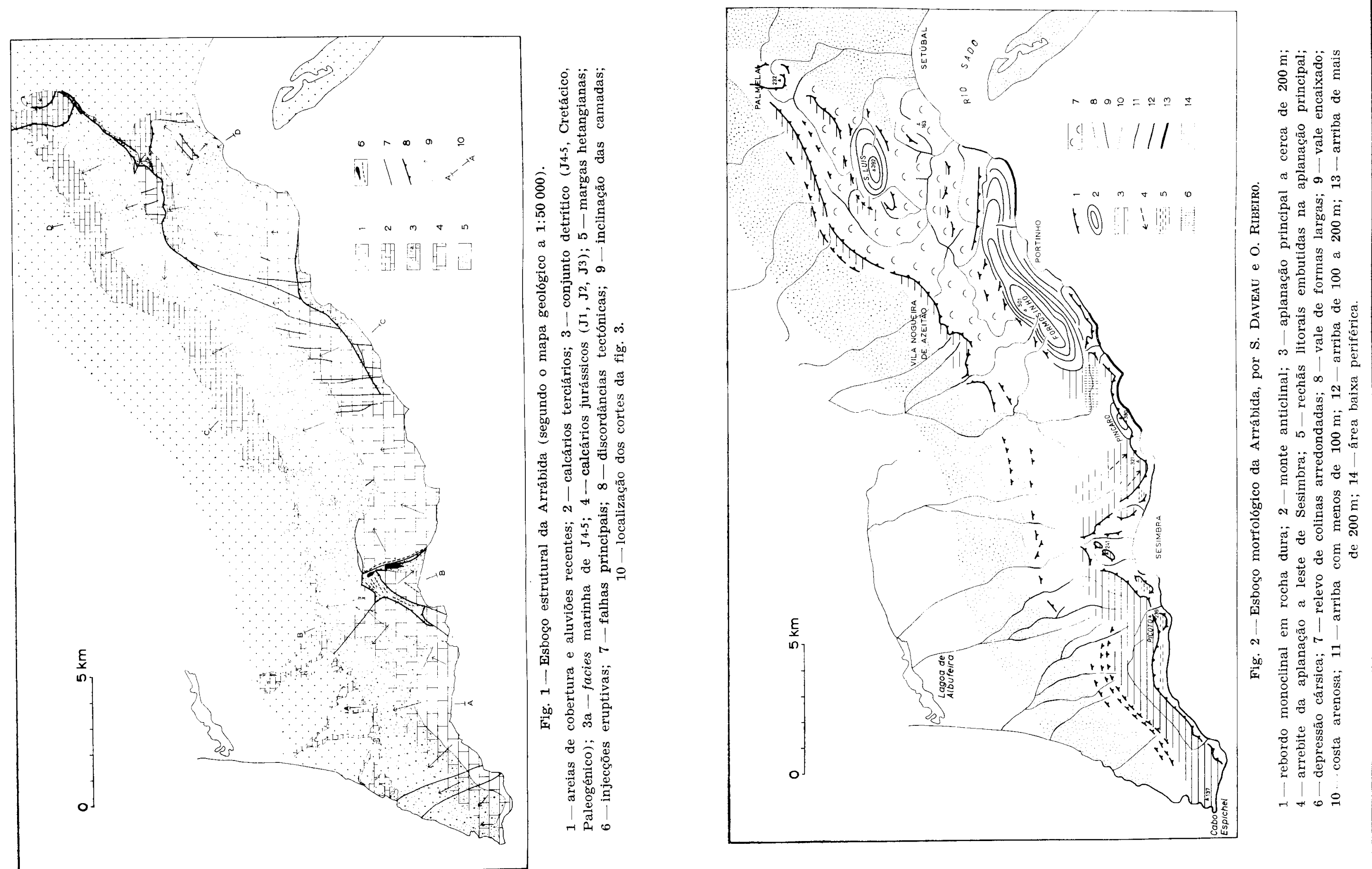
A erosão penetrou sem esforço nestes terrenos mal consolidados, abrindo um sistema de vales e criando condições favoráveis à agricultura, que se detém bruscamente no contacto com os calcários do núcleo montanhoso.

5) O retorno transgressivo do mar miocénico é fenómeno muito geral mas não afectou senão a orla do continente. Quando se alargou a área vestibular das depressões do Tejo e do Sado, já em parte colmatadas por sedimentos continentais paleogénicos, certos relevos próximos devem ter formado ilhas: entre eles alguns morros calcários da Arrábida e a Serra de Sintra, em parte ainda protegida pela cobertura de calcários, tornados resistentes pelo metamorfismo da massa eruptiva. Conservado nalguns retalhos no interior da cordilheira, envolvendo-a completamente pelo norte, o Miocénico constitui, com as bancadas calcárias sobrepostas ao conjunto detrítico, a cornija de uma imponente costeira, ao passo que os seus solos, de sofrível qualidade, sustentaram a relativa prosperidade agrária das aldeias de Azeitão.

6) No fim do Miocénico produziu-se o surto tectónico principal, responsável, como provàvelmente em toda a orla, pelo arranjo estrutural donde a erosão desentranhou o relevo actual (fig. 2 e 3 ). Mais uma vez se nota o contraste entre o leste e o oeste: enquanto na área do Cabo se deu um grande dobramento de conjunto, mais vigoroso em profundidade (pendor muito forte nas camadas jurássicas, forte nas cretácicas, fraco nas miocénicas), os anticlinais orientais são dissimétricos, tombados para o sul, falhados e laminados no flanco meridional (camadas do Jurássico inferior cavalgam o Miocénico); finalmente, na dupla escama de Palmela, os calcários do Helvetiano correram sobre formações que vão do Jurássico superior até ao próprio Helvetiano - o que permite datar com mais precisão o acidente: entre as camadas que afecta e o Pliocénico sensivelmente horizontal.

7) Este período marca, assim, o começo da estabilidade: apenas movimentos póstumos, deformações de grande raio, vão interferir com o abaixamento rítmico do nível do mar que, durante as pausas, afeiçoa superfícies de abrasão e, nas descidas, comanda o aprofundar da rede hidrográfica e a correlativa erosão diferencial, que valoriza ao máximo os núcleos calcários dos anticlinais. Toda a Arrábida é uma área de ressonância sísmica e, mais vezes do que Lisboa, Setúbal sentiu os efeitos de tremores de terra catastróficos: o último, em 1858, causou ruínas em 576 edifícios, 90 dos quais caíram completamente.

ARranjo Estrutural e EVolução Morfológica

A Arrábida é constituída por três linhas de anticlinais, dispostas em corrediça, cujo eixo está orientado sensìvelmente ENE-OSO (fig: 2).

Dos anticlinais da primeira linha resta apenas uma parte do flanco norte, que se despenha no mar por grandes escarpas de falha, poderosamente retocadas pela abrasão (fig. 3, A). Uma série de desligamentos transversais, de direcção N-S ou NNE-OSO, não tem grande influência no relevo. Sem nos embrenharmos na interpretação tectónica, é curioso aproximar estes rumos dos que produziram o rejuvenescimento do relevo do soco (subida em degraus da Cordilheira Central) ou fizeram rejogar velhas fracturas: fossos de Trás-os-Montes, prolongados pelo norte da Beira, falhas marginais do maciço antigo. Assim, são provàvelmente as linhas de fraqueza do substrato profundo, que surge a pouca distância na bacia do Sic ' , que orientaram os dobramentos e fracturas da cobertura plástica.

Até ao Portinho, desenrola-se um litoral mediterrâneo típico, onde o brutal mergulho para terra dos estratos calcários e grandes escarpas de falha geram as arribas mais alterosas do litoral ocidental da Península, sobranceiras a um mar sereno e luminoso, abrigado dos quadrantes ventosos pela massa do relevo. A costa descai ràpidamente para grandes profundidades, com um entalhe produzido pelo recuo da arriba, que a disposição das camadas favorece. O Píncaro, cume da serra do Risco $(380 \mathrm{~m})$, marca o lugar mais alto da arriba, vendo-se os estratos de pernada do anticlinal despenharem-se bruscamente no mar. Duas baías interrompem o contorno marítimo da Arrábida, ambas elas de origem estrutural: uma exígua - o Portinho - , corresponde ao encurvamento do eixo do anticlinal do Formosinho, onde está o ponto culminante da Arrábida (501 m); outra, mais vasta, foi produzida pela abrasão em camadas friáveis (margas do Neojurássico, arenitos do Cretácico), entre os potentes encontros calcários do 




(B)

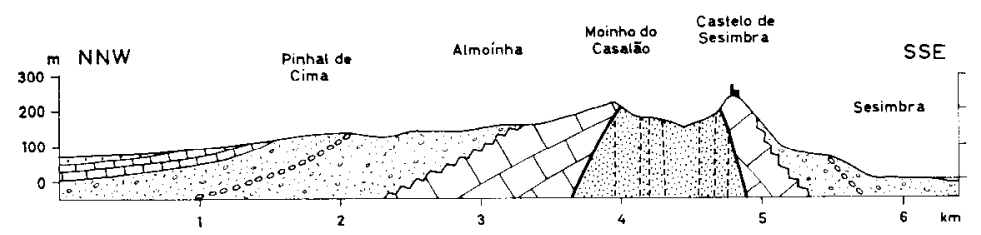

(c)
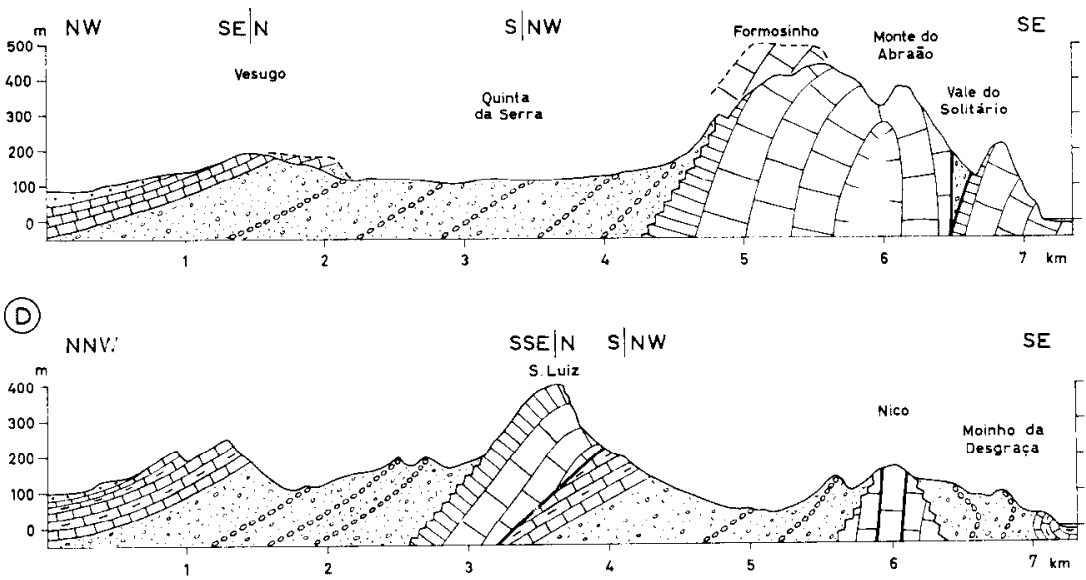



Fig. 3-Cortes transversais (ver a localização na fig. 1),

1 - areias de cobertura; 2-calcários terciários; 3 - conjunto detrítico ( $\mathrm{J} 4-5$, Cretácico, Paleogénico); 4 - facies marinha de $\mathrm{J} 4-5 ; 5$ - calcários do Lusitaniano (J3);6 - calcários $\mathbf{J} 2$ e $\mathbf{J} 1 ; 7$ - margas hetangianas; 8 -injecções eruptivas; 9 -falhas e contactos anormais; $10 \quad$ discordâncias
Cerro de Ares e do Forte do Cavalo. Um acidente diapírico ramificado, com injecções de rochas básicas, traz à superfície as margas hetangianas, fortemente comprimidas entre carapaças calcárias. Um fragmento delas, talvez deslocado recentemente, forma as colinas do Castelo e do Moinho da Forca, que dominam a cerrada aglomeração de pescadores de Sesimbra (fig. 3, B)

Toda a frente marítima de Portugal conserva o cunho da acção abrasiva do mar que, desde o Pliocénico, a despeito de retornos episódicos, foi recuando até à posição actual. Este tema, que voltaremos a encontrar, é ilustrado na Arrábida por uma bela plataforma de abrasão, que rasoirou todo o relevo até à base do Risco e do Formosinho. Quando se volta do Cabo é sugestiva a aplanação perfeita, donde «emergem» apenas o morro do castelo de Sesimbra e aqueles anticlinais verdadeiras ilhas desse mar que a observação restitui sem esforço. Os movimentos póstumos (facilitados talvez pela plasticidade das margas gipsiferas), actuando no sentido das deslocações tectónicas de grande estilo, deformaram esta plataforma: aparentemente estável na área do Cabo $(150-170 \mathrm{~m})$, arrebita-se, no Picote até $240 \mathrm{~m}$ e sobe visivelmente, no Cerro de Ares, até $320 \mathrm{~m}$ (fig. 4). Só um estudo minucioso desta superfície ${ }_{\text {monde }}$ se encontram esparsos seixos bem rolados, e das rechãs que a entalham do lado do mar ou testemunham regularizacóes locais ao longe de antigas linhas de drenagem, permitirá separar deformações e embutimentos, o que é devido à acção da tardia instabilidade tectónica e o que pode imputar-se a erosâo durante as pausas marinhas do Quaternário.

O Espichel foi, até ao século $\mathrm{xv}$, «um dos cabos do mundo», cuja grandeza selvagem impressionara os antigos e the valeu o nome de Promontorium Barbaricum. Despenha-se de $140 \mathrm{~m}$ de altura, pelo sul numa arriba a pique, pelo oeste nas grandes lajes formadas pelos estratos calcários, minadas na base pelo embate das vagas. O próprio mar é diferente, sereno e azul de um lado, não raro encapelado e sombrio do outro. Uma ermida do século xvIII, flanqueada das correntezas de casas onde se alojavam os «círios» (peregrinações que ofereciam uma grande vela de cera a Nossa Senhora), recorda um lugar de romaria frequentado desde 



Fig. 4-Dois panoramas do castelo de Sesimbra (figura extraída de O. Ribeiro, Geografía de España y Portugal, t. v).

Em cima, para oeste: plataforma de abrasão do Cabo Espichel, rechãs litorais embutidas nela, ligeiro arrebite da superfície nos primeiros planos. Em baixo, para leste: deformação evidente da plataforma de abrasão, rechãs embutidas nela; ao longe, figurando ilhas, o flanco norte do anticlinal do Risco (Píncaro) e o monte anticlinal do Formosinho.

a Idade Média. Como tantas vezes acontece, os devotos antecederam os turistas.

O mar trabalha como uma rasoira e, como esta, bruscamente detém a sua acção. Por alturas da serra do Risco as formas estruturais dominam a paisagem. A erosão diferenciạ exumou os núcleos calcários dos antiçlinais da sua cobertura detrítica, deixando à vista a subida estrutural das camadas que coincidem, pelo norte, com a superfície topográfica, e festões de cornijas que, no flanco meridional, indicam o mergulho das camadas invertidas. Quanto maiores forem as surgências de calcário tanto maiores são os montes a que dão origem: assim, o anticlinal do Viso, a oeste de Setúbal, está recortado em colinas na brecha neojurássica, dominado pela mole imponente da serra de São Luís ( $392 \mathrm{~m}$ ), coroada pelas potentes assentadas do Liássico (fig. $3, \mathrm{c}$ e D).
Todo o conjunto detrítico foi presa fácil da erosão. Sobranceiras a ele, as bancadas de calcário terciário desenham uma imponente costeira. Como o pendor destas camadas diminui para oeste, a costeira é quase um hog back entre Palmela e a Portela das Necessidades e reduz-se por alturas do Calhariz, onde uma mancha de areias pliocénicas se insinua (e com ela o pinhal e a charneca) no interior da cordilheira. A cornija principal ora é constituída por uma potente bancada da base do Miocénico ora por um horizonte calcário paleogénico; às vezes o degrau monoclinal desdobra-se, formando ambos os elementos um duplo ressalto. Uma ou outra vez a costeira está biselada e com as suas alturas acertam cimos aplanados nas formações brandas do Neojurássico. $O$ ponto de partida do modelado actual seria assim uma aplanação parcial, que se deteve de encontro à resistência dos calcários muito levantados do núcleo dos anticlinais. Por comparação com a plataforma do Cabo, onde tudo foi arrasado, é lícito pensar no desenvolvimento incompleto de uma superfície de desnudação subaérea. A rede inicial, consequente, domina ainda na metade ocidental da Arrábida, onde ribeiros e arroios correm, de leste para oeste, para o Tejo, a Lagoa de Albufeira e as arribas atlânticas. Abaixo da plataforma do Cabo apenas começam a desentranhar-se, muito fragmentados pela rede hidrográfica, outeiros alinhados, correspondentes a surgệncias de estratos durọs, que são aqui arenitos bem consolidados do Cretácico: o Miocénico, pouco inclinado e encoberto pelas areias posteriores, segue-se, no fundo dos valeiros, até à Lagoa de Albufeira.

Nos vales da parte oriental da cordilheira intervieram já as complicações próprias da evolução da drenagem: uma linha de água subsequente percorre o Vale do Picheleiro e recebe a Ribeira de Alcube, subsequente também. Neste outro vale produziu-se uma captura pelo recuo das cabeceiras da Ribeira do Livramento, que se lança no Sado em Setúbal, favorecida pelo menor percurso; o velho caminho de carro que sai de Palmela percorre o fundo do vale abandonado, dominado ao norte pela cornija calcária coroada de moinhos, e suspenso, ao sul, sobre as formas vigorosas do entalhe que, em parte, decapitou a ribeira que corria pelo seu talweg. 
Dá-se geralmente a Lagoa de Albufeira como o último resto de um percurso antigo do Tejo. Tal interpretação é insustentável. A lagoa ocupa o ponto mais deprimido do sipclinal miocénice, constituído quando se deram as últimas deformações da Arrábida e verosìmilmente acentuado pelos movimentos que continuam a soerguer a cordilheira e a aprofundar o sulco tectónico que constitui o seu limite. Claro que se um rio importante por aqui passasse ele ficaria preso por uma espécie de goteira que definia o seu leito. $O$ que se pode dizer é que esse dispositivo favoreceu a ingressão marinha, enquanto, até horizontes elevados, continuavam a chegar acarreios de seixos originários das formações eruptivas de Sintra e dos arredores de Lisboa. O entalhe do gargalo terminal do Tejo não existia até essa data e só se define quando esses acarreios cessam: é então que se produz um sistema de fracturas E-O (provàvelmente de distensão), que facilitaram a ingressão do mar numa depressão prefigurada (e porventura acentuada) pela estrutura. $\mathrm{Na}$ verdade, o chamado «estuário» é um golfo marinho, no fundo do qual o Tejo desagua pelo delta dos Mouchões. Aqui, como em todo - seu percurso, pode demonstrar-se a sua extrema modernidade e a rapidez com que se organiza um grande aparelho fluvial.

\section{VEGETAÇÃO}

A Arrábida tira o nome dum ribat muçulmano, retiro de oração e de preparação para a guerra santa; nos meados do século xvi, estabeleceu-se, na encosta sobranceira ao Portinho, uma comunidade de ermitas, protegida no seu voluntário isolamento pelos bosques, e penhascos.

Pelo contraste entre terrenos siliciosos e terrenos calcários, pela exposição ao sul de parte das vertentes mais abrigadas, pelo bravio do relevo, pela falta de água, pela tardia ocupação humana, a Arrábida reveste-se ainda de uma vegetação «natural», restos de uma mata com um sub-bosque denso de arbustos de grande porte. A árvore dominante é o carvalho português (Quercus lusitanica), de folha que cai tarde e renasce cedo, às vezes associado ao sobreiro e à azinheira, Querci de folha perene, e, nos lugares mais abri- gados, à alfarrobeira, que só no Algarve forma povoamentos importantes, propagada pela cultura; mas a maior extensão da mata é constituída por espécies arbustivas, que aqui tomam porte arbóreo: medronheiro, murta, folhado (Viburnum tinus), aderno (Phillyrea latifolia), algumas urzes arbóreas. A mata só se conserva no abrigo dos vales e encostas meridionais ou nos fundos entalhes de erosão que, pelo norte, penetram na massa calcária, onde se encontra protegida pela natureza e foi poupada pelo homem. No resto domina um maquis arbustivo, mais ou menos degradado por pastores e carvoeiros, constituído principalmente por aroeira (lentisco) e carrasco (Quercus coccifera), com o cortejo de plantas odoríferás, alecrim e tomilhos: no conjunto, uma vegetação mediterrânea, meridional portanto, onde o carvalho português introduz uma cambiante atlântica. "Mas aqui a doçura do clima deixa que os arbustos tomem o porte das árvores, elevando-se a $6 \mathrm{e}$ 8 metros de altura. Os troncos de alguns adernos atingem meio metro de diâmetro e os medronheiros tomam formas gigantescas. O maciço vegetal é impenetrável: as copas tocam-se, os troncos entrelaçam-se, os arbustos prendem-se uns nos outros, as trepadeiras e silvas enleiam-se, de tal forma que há plantas mortas e desenraizadas, com o tronco a apodrecer, que se conservam de pé por não terem espaço para onde cair. Reina um silêncio profundo e uma luz amortecida. $\mathrm{Na}$ camada de húmus, abrigados pela sombra da folhagem, medram alguns fetos. Tudo isto evoca a ideia de floresta virgem, sob clima mais rico de calor e humidade em outras zonas ou em épocas mais remotas da história do globo.» (O. RIBEIRo, 1935). Algumas sementes, presas à lã das ovelhas ou ao pêlo das cabras, introduziram espécies próprias dos terrenos siliciosos na periferia dos maciços calcários. Os povoamentos quase exclusivos de estevas devem-se a queimadas e à selecção produzida pelo gado, a que repugna este arbusto coberto de resina, amarga e de cheiro intenso. Entre o núcleo calcário e a costeira, a agricultura - principalmente seara. e vinha - penetrou nos terrenos friáveis do Vale do Picheleiro e da sua bifurcação oriental, adaptando-se estreitamente ao conjunto detrítico e detendo-se contra os relevos; nos solos mais cascalhentos, que a agricultura não conseguiu conquistar, 
há rodais de pinheiros, bravos e mansos, de rearborização recente.

\section{OCUPAÇÃO HUMANA}

Sob o aspecto humano, nesta montanha repulsiva, quase toda a ocupação da Arrábida é periférica:

1) Palmela, grande vila ainda aninhada no seu morro, de casas brancas e ruas acanhadas, comanda as vastas planuras de sopé, coroada por um castelo que foi sede da Ordem de Santiago, vigiando simbòlicamente uma das entradas das terras baixas do Sul, que aquela ordem incorporou no território nacional. E muito instrutivo o contraste de paisagem que se observa do castelo: para o sul, hortas, laranjais e quintas dos arredores de Setúbal indicam a ocupação agrária antiga e intensa que, graças à rega, constitui a auréola típica das cidades meridionais; para o norte, os contornos geométricos das vinhas, olivais, campos de trigo e até pinhais e eucaliptais, salpicados de casas disseminadas, constituem uma paisagem de colonização, que transformou as charnecas, à força de estrume e de trabalho, num dos centros abastecedores da capital e das aglomerações próximas.

2) Uma cadeia de aldeias antigas e prestigiosas, onde a corte e a fidalguia vinham passar o Verão nos séculos XVII e XVIII, com velhos palácios e certo ar urbano, ocupa a base do reverso da costeira. A gente grada vinha para aqui atraída pela caça grossa (lobos, javalis, ursos) que se criava nas brenhas da serra e, descendo ao vale, atacava homens e gados e ameaçava os terrenos de cultura. Nos meados do século XVIII, no contexto das medidas de fomento do Marquês de Pombal, cria-se o concelho de Azeitão (1759, incorporado no de Setúbal um século depois) e o Rei, a rogo dos povos, mandou descoutar o terreno próximo: era o triunfo da utilidade sobre antigos privilégios da nobreza ociosa. Nos alvores da indústria moderna houve aqui fábricas de tecidos de algodão, de tintas e de estamparia. Nos meados do século XIX, um agricultor progressivo arroteou grande parte dos vales, plantando as vinhas que dão uma grande variedade de vinhos generosos e de mesa, todos excelentes, com algumas colheitas famosas vendidas por bom preço. Duas paisagens rurais se podem observar: uma recente, no vale do Picheleiro, entre a costeira e os montes calcários, outra antiga, com olivais centenários, que deram o nome a Azeitão (do árabe: 'olival'), campos de semeadura, hortas e formosos jardins, no reverso, limitada pelo contacto das argilas, margas e calcários miocénicos, que dão solos razoáveis, com as areias e cascalheiras posteriores. Azeitão é um verdadeiro «nom de pays»e serve de complemento a algumas das doze povoações que o constituem, desde Quinta do Anjo a Aldeia de S. Pedro, todas no contacto entre os dois tipos de terrenos. A partir delas se fez, no último século, a ocupação da planura bravia em regime de enfiteuse, alargando-se a terra cultivada e o seu nome de conjunto: Brejos de Azeitão é bem significativo do processo. Em todo o norte da Arrábida a antiga ocupação agrária se expandiu por uma verdadeira colonização de charnecas, com todos os sentidos que esta palavra comporta: valorização de terras novas (vinha, olival, montado de sobro, horta), ocupação humana $a b$ ovo, contactos de civilização entre gente vinda do Norte («Caramelos» do Baixo Mondego, que começaram por vir trabalhar nos arrozais — «Caramelos de ir e vir» - e acabaram por fixar-se — «Caramelos de estar») e do Sul (Alentejanos que, rompendo terras bravias, fizeram disso um modo de vida e nestas últimas arroteias se fixaram). Para o norte, separando esta ocupação rural do conjunto de terras e de vilas que marginam o estuário (que hoje formam, em grande parte, subúrbios residenciais e industriais de Lisboa), o pinhal (às vezes o eucaliptal) ocupa os solos arenosos e cascalhentos, criando vigoroso contraste entre eles e a horticultura minuciosa dos fundos aluviais. Eram as charnecas onde, até ao século XIX, Lisboa se abastecia de lenha e carvão. A Arrábida conservou-se assim, até aos nossos dias, uma área isolada, onde não houve o cuidado de preservar as suas matas antes de se abrirem estradas donde se contemplam panoramas de rara beleza.

3) Sesimbra, constrangida no fundo do seu «vale tifónico», coroada por um castelo altaneiro há muito abandonado, é uma grande aglomeração inteiramente dominada pela pesca (recentemente também pelo veraneio e pelo turismo); abre-se para o mar por uma baía abrigada, rica de plâncton e portanto de cardumes de peixe, pescado com aparelhos de linha por uma frota de pequenas embarcações que, à noite e de manhã, 
saem para a sua faina. O regresso começa ao fim da manhã e ao cair da tarde: pode avaliar a importância da pesca quem assiste à lota. Os peixes são dispostos artìsticamente na praia, segundo as espécies, uns em cima de montículos de areia, outros apenas alinhados, sob o olhar vigilante da Guarda Fiscal, que arrecada o imposto do «pescado», outrora à luz de archotes, hoje à de potentes reflectores; os compradores arrematam com um «chui» discreto quando lhes convém o preço, anunciado com incrivel rapidez em ordem decrescente. Burros, carrocas, camionetas, transportam o peixe para mercados próximos ou distantes. Durante a noite ouve-se constantemente o rolar surdo das camionetas que sobem a estrada íngreme em direcção ao grande centro consumidor de Lisboa. Outrora com indústrias de conservas e de cordoaria, Sesimbra conserva ainda hábeis construtores de pequenas embarcações, dentro de uma tradição artesanal e familiar. A construção de um molhe no extremo oeste da baía criou um abrigo para os temporais; mas o porto fica longe, o moderno bairro dos pescadores num alto do extremo oposto. Estes habitam as casinhas da vila, onde se guardam, no rés-do-chão, os utensílios da «companha»: as bóias de cabaça (abóbora), pintadas de cores diferentes, distinguem cada uma delas. Por isso, a frota de pesca está quase sempre ancorada em frente da praia e da povoação. Nos últimos anos, hotéis e construções modernas introduziram grande número de ociosos e de extravagantes entre a população laboriosa [MARIA ALfReda CRUz, Pesca e Pescadores em Sesimbra (Chorographia), Lisboa, 1966].

4) Setúbal é uma típica cidade de contacto: contacto entre a terra e o mar, contacto entre o oceano e um rio navegável a que dá saída, contacto entre o último relevo calcário da orla estremenha e as planuras que anunciam o Alentejo. Esta posição explica, por um lado, as funções variadas do porto: navegação de alto bordo, cabotagem e pesca (o segundo centro do país, com importantes fábricas de conserva); por outro, o rico alfoz rural que envolve a cidade: hortas e laranjais, regados de poços (noras, hoje motores) que criavam a chamada Baixa de Palmela, rica dos mananciais alimentados pela cortina de relevo. No remanso das águas interiores, em sapais conquistados por valadores exímios, ainda se vêem salinas, do tempo em que o salgado de Setúbal, com as grandes navegações portuguesas do século XVI, tomou preponderância sobre os outros: hoje os arrozais vão substituindo as marinhas, de tal modo o sal se desvalorizou; e as laranjas de Setúbal, outrora exportadas para o Norte da Europa, não se adaptaram ao mercado internacional. A despeito da proximidade da capital, numa posição de certo modo homóloga, Setúbal foi, durante quase um século, a terceira cidade de Portugal e ainda hoje (44000 habitantes) ocupa lugar de relevo entre as que se seguem a Lisboa e ao Porto.

ORLANDO RIBEIRO 